\title{
PENGEMBANGAN TRANSIT ORIENTED DEVELOPMENT UNTUK MENINGKATKAN KELANCARAN LALU LINTAS DI LEBAK BULUS
}

\author{
Irwan $^{1}$, Giovanni Pranata ${ }^{2}$, dan Johannes Susanto ${ }^{3}$ \\ ${ }^{1}$ Program Studi Sarjana Teknik Sipil, Universitas Tarumanagara, Jl. Letjen S. Parman No.1 Jakarta \\ Irwan.325150144@stu.untar.ac.id \\ ${ }^{2}$ Program Studi Sarjana Teknik Sipil, Universitas Tarumanagara, Jl. Letjen S. Parman No.1 Jakarta \\ giovannip@ft.untar.ac.id \\ ${ }^{3}$ Program Studi Sarjana Teknik Sipil, Universitas Tarumanagara, Jl. Letjen S. Parman No.1 Jakarta \\ jo.susantobsp@gmail.com
}

Masuk: 10-01-2021, revisi: 08-03-2021, diterima untuk diterbitkan: 09-03-2021

\begin{abstract}
Transportation is one of the most important components for every aspect of society in this world. Therefore, the TOD concept is needed in the implementation of transportation. At the present time, traffic jams often occur such as congestion of vehicles caused by people who do not want to walk. Actually this is because the place the people wants to go to is located far enough that it requires people to use private vehicles. The TOD concept is needed to solve this problem. To narrow down the research, the research was carried out in one place, namely in the Lebak Bulus area. In addition, it is also necessary to know the travel routes in the area and how the TOD is developed in Lebak Bulus. Researchers used data from respondents' responses consisting of MRT users and people in the surrounding area. The questionnaire was made to determine the desire or motivation of the people in walking, to find out about traffic conditions, and the condition of the MRT and its supporting areas in Lebak Bulus. The analysis carried out was by conducting online questionnaires. The development of the TOD area is needed to reduce congestion in the area.
\end{abstract}

Keywords: Transportasion; TOD Concept; TOD in Lebak Bulus; MRT

\begin{abstract}
ABSTRAK
Transportasi merupakan salah satu komponen terpenting bagi setiap aspek masyarakat di dunia ini tak terkecuali bagi masyarakat di Indonesia. Oleh sebab itu konsep TOD sangat dibutuhkan dalam pelaksanaan transportasi. Pada masa sekarang sering sekali terjadi kemacetan seperti padatnya ruas kendaraan yang disebabkan oleh masyarakat yang tidak mau berjalan kaki. Sebenarnya hal ini juga disebabkan karena tempat yang ingin dituju oleh masyarakat tersebut terletak cukup jauh sehingga mengharuskan masyarakat untuk menggunakan kendaraan pribadi. Konsep TOD diperlukan untuk mengatasi masalah tersebut. Untuk mempersempit penelitian maka penelitian dilakukan di satu tempat saja yaitu di daerah Lebak Bulus. Selain itu perlu juga untuk mengetahui rute perjalanan di daerah tersebut dan bagaimana pengembangan TOD di Lebak Bulus. Peneliti mengunakan data dari tanggapan responden yang terdiri dari pengguna MRT dan masyarakat di daerah sekitar. Kuisioner dibuat untuk mengetahui keinginan atau motivasi masayarakat dalam berjalan kaki, untuk mengetahui tentang kondisi lalu lintas, dan kondisi MRT dan area penunjangnya di Lebak Bulus. Analisis yang dilakukan adalah dengan melakukan quisioner secara online. Pengembangan kawasan TOD diperlukan untuk mengurangi kemacetan yang terjadi di daerah tersebut.
\end{abstract}

Kata kunci: transportasi; konsep TOD; TOD di Lebak Bulus; MRT

\section{PENDAHULUAN}

Masalah transportasi menjadi salah satu yang selalu terjadi dimanapun pada masa sekarang ini. Dimanapun terutama di kota-kota besar masalah ini menjadi masalah yang sangat serius. Kemacetan, jalan yang sangat padat, polusi udara yang terjadi merupakan beberapa masalah yang terjadi dari masalah transportasi. Permasalahan transportasi yang terjadi saat ini sangat berhubungan dengan pola tata guna lahan, hal ini disebabkan pola tata guna lahan mempunyai peran yang penting dalam hal menentukan aktivitas dan kegiatan yang dilakukan oleh masyarakat. Aktivitas dan kegiatan masyarakat dapat ditekan dari segi pemanfaatan tata guna lahan dan aksesibilitas dalam menjangkau kegiatan tersebut. Pada dasarnya, tingginya aktivitas masyarakat yang ditimbulkan 
Bulus

dan pemanfaatan tata guna lahan yang tidak diiringi dengan aksesibilitas yang baik menyebabkan terjadinya kemacetan dan masalh transportasi yang lainnya pada masa sekarang ini. Jumlah pergerakan masyarakat dalam menggunakan moda transportasi, yang terutama adalah pengguna transportasi pribadi semakin lama semakin meningkat. Hal ini yang menimbulkan masalah dan ketidak-efektifan antara aktifitas masyarakat dengan aksesibilitas yang tersedia. Karena keterkaitan antara pemilihan aksesibilitas moda transportasi dan pola pemanfaatan guna transportasi untuk mendukung pemanfaatan guna lahan tersebut sangat erat, maka diperlukan suatu sistem perancangan yang dapat mengintegrasi antara pemanfaatan guna lahan di sekitar dengan pembangunan moda transportasi yang bertujuan untuk menunjang aktifitas dan keperluan masyarakat yang dapat dikatakan sebagai salah satu pengguna moda transportasi. Sistem perancangan yang mengintegrasi antara pemanfaatan guna lahan sekitar dengan moda transportasi dapat disebut juga dengan konsep Transit Oriented Development (TOD). TOD sendiri sebenarnya sudah tidak asing lagi bagi masyarakat di dunia ini. Di Amerika Serikat TOD sudah diperkenalkan pada akhir abad 19 atau bisa disebut juga pada awal abad ke 20. Sampai sekarang banyak Negara yang sudah mengunakan konsep TOD tak terkecuali di Negara Indonesia. Di wilayah kota Jakata khususnya di daerah Lebak Bulus, konsep TOD sedang dikembangkan. Di daerah tersebut sudah memiliki stasiun MRT dan stasiun BRT yang nantinya akan saling terintegerasi dengan berbagai fasilitas yang berada di sekitar sana. Transit Plaza Lebak Bulus nantinya juga akan dibangun di sekitar sana.

\section{Definisi Transit Oriented Development}

Konsep Transit Oriented Development sebenarnya memiliki berbagai macam definisi yang memiliki beberapa kesamaan dalam konsep pemahamannya dan prinsip dasarnya. Oleh karena itu definisi dari TOD itu sendiri adalah konsep pengembangan/pembangunan suatu kawasan yang bersifat mixed use dan compact yang berada dalam jangkauan jarak berjalan kaki dari titik layanan angkutan massal dan pusat kawasan komersial.

\section{Pembagian tempat pada kawasan TOD}

Kawasan TOD terbagi menjadi 5 tempat sesuai dengan tata guna lahan yang ada (Griffin, 2004):

1. Pusat komersial adalah area yang dimanfaatkan untuk kepentingan komersial berupa area perdagangan, perkantoran, rumah makan, pusat hiburan seperti bioskop ataupun mall, industri ringan, serta fungsi komersial lainnya. Area pusat komersial sebaiknya berada di pusat kawasan TOD dan berada dekat dengan lokasi titik transit sehingga dapat diakses oleh masyarakat dengan mudah seperti berjalan kaki atatupun dengan naik sepeda, serta dilengkapi dengan keberadaan ruang hijau.

2. Permukiman merupakan area yang transit, fasilitas publik, dan pusat komersial dengan berbagai macam guna lahan permukiman dengan tipe, kepadatan, dan harga yang bervariasi.

3. Fasilitas publik, merupakan area dengan karakteristik fungsi guna lahan sebagai tempat atau tujuan dari aktivitas masyarakat, memiliki tingkat visibilitas yang tinggi dengan ciri-ciri fisik yang umumnya dilengkapi dengan ruang publik berupa taman atau mall. Jenis pemanfaatan ruang lainya yang dapat dikembangkan di dalam area ini adalah kantor pemerintahan, perpustakaan, kantor polisi, kantor pemadam kebakaran, rumah sakit, pasar swalayan, serta jenis pemanfaatan ruang lainnya yang berorientasi pada pemenuhan kepentingan publik.

4. Secondary area merupakan area yang berada di luar kawasan transit dengan dominasi pergerakan menggunakan kendaraan pribadi serta kepadatan bangunan yang relatif rendah. Jenis pemanfaatan ruang yang ada pada area ini adalah hunian tipe rumah tunggal, sekolah umum, kawasan industri besar, pertokoan, serta permukiman perdesaan.

5. Fungsi-fungsi lain merupakan segmen yang tata guna lahanny berada diluar dari fungsi- fungsi diatas seperti pemukiman, fasilitas publik, pusat komersial, dan juga secondary area. Segmen ini dapat beraada baik di dalam maupun diluar kawasan transit dengan jenis guna lahan seperti jalur kereta api.

\section{Prinsip dan indikator konsep TOD}

Suatu wilayah yang dalam proses pembangunan ataupun pengembangan dalam kawasan TOD harus memiliki karakteistik untama yang menggambarkan penerapn dari konsep TOD tersebut. Karakteristik utama tersebut dapat dijelaskan dengan lebih rinci lagi ke dalam prinsip dan indikator kawasan TOD. Prinsip dan indikator dlam konsep TOD tersebut antara lain adalah:

1. Densify atau kepadatan merupakan pola tata ruang yang padat dan juga rapat, dengan meningkatkan atau mengembangkan kota secara densifiksi dibandingkan deengan pertummbuhan kota secara horizontal (sprawl). Menurut TCRP (2002) tingkat kepadatan hunian atau kepadatan lahan yang dapat menjelaskan prinsip kepadatan. Sementara ITDP (2015) cenderung memperhatikan tingkat kepadatan penggunaan lahan, dengan berpedoman pada nilai koefisien dasar bangunan (KDB) dan koefisien lantai bangunan 
(KLB). Kepadatan penggunaan lahan akan mendekatkan berbagai aktivitas hingga pemanfaatan moda transportasi umum dapat dimaksimalkan.

2. Land-Use Mixes memliki tujuan untuk mendukung efisiensi mobilitas dan meningkatkan invablity dengan menghubungkan hunian-hunan yang ada dengan sekolah, area perkantoran, dan area perdagangan seperti mall. Prinsip ini bertujuan untuk saling menghubungkan antar guna lahan yang berkaitan sehingga dapat mendorong masyarakat untuk bersepeda ataupun berjalan kaki (ITDP, 2015). TCRP (2002) membagi property mixed-uses ke dalam dua hal yang merupakan jumlah guna lahan mixed-uses dan keberadaan retail dengan skala pelayanan yang beragam.

3. Interkoneksi antar jaringan jalan dan blok diperlukan untuk membentuk lingkungan yang walkable. Halhal yang memperlambat laju kendaraan seperti jaringan jalan yang padat dan komposisi jalan-jalan yang kecil dan juga jumlah persimpangan jalan yang tinggi dapat memberikan keuntungan bagi pejalan kaki. Untuk mengetahui tingkat interkoneksi jaringan jalan dan blok, Cara yang dapat digunakan yaitu dengan menghitung jumlah persimpangan yang ada di suatu kawasan. Semakin banyak persimpangan yang ditemui maka semakin tinggi tingkat interkoneksi jaringan jalan dan blok.

4. Parkir dalam konsep TOD diarahkan pada sistem pembatasan lahan dengan penyediaan ruang lahan yang lebih sedikit pada pusat kawasan transit dibandingkan pada area pinggiran kota/secondary area. Salah satu metode pembatasan lahan adalah metode dengan menyediakan area/ lahan kolektif. Metode ini mampu mengakomodasi kebutuhan area di titik transit dan atau kawasan transit dengan meningkatkan efisiensi lahan dan membatasi lahan area individu. Parkir dengan metode ini biasanya berupa gedung, kantor, atau fasilitas titik transit itu sendiri.

5. Jalur Pedestrian diperlukan untuk mendukung pergerakan yang berorientasi pada pemakaian transportasi umum massal, dengan menyiapkan infrastruktur yang dapat memberikan keamanan dan juga kenyamanan bagi setiap pejalan kaki maupun bagi setiap pesepeda.

6. Ruang terbuka memliki peran sebagai wadah interaksi sekaligus menciptakan keserasian yang lengkap di tengah tingginya intensitas penggunaan lahan. Lokasi ruang terbuka pada kawasan yang memiliki konsep TOD biasanya berada di dekat titik transit, area perdagangan, dan juga area pemukiman.

\section{Kendala dalam konsep TOD}

Keberhasilan dari penerapan konsep TOD terhadap suatu kawasan seringkali menjadi terhambat yang disebabkan oleh berbagai alasan (Porter, 1998):

1. Lahan yang terpisah-pisah. Sekumpulan lahan kecil, potongan lahan dengan berbagai kepemilikan menjadi alasan penghambat pengembangan TOD

2. Ketidakpastian pasar. Para pengembang terkadang mempertanyakan/ tidak yakin dengan finansial dari proyek TOD

3. Dukungan politis. Dalam membangun suatu kawasan TOD diperlukan dukungan dari phak politik secara maksimal

4. Pasar real estate tertekan. Keberhasilan TOD terkait dengan nilai jual dari real estate di daerah sekitar

5. Waktu: Re-organisasi pola pembangunan wilayah sekitar sistem angkutan massal dan pengembangan dari kawasan TOD agar dapat berfungsi secara maksimal terkadang berjalan sangat lamban sehingga dapat memakan waktu hingga mencapai puluhan tahun.

\section{Opini tentang pengembangan TOD di Jakarta}

Mengacu pada Peraturan Daerah No. 1 Tahun 2012 yang menjelaskan Rencana Tata Ruang Wilayah DKI Jakarta 2030, konsep TOD merupakan bagian dan rencana pembangunan tata ruang wilayah DKI Jakarta yang akan dilakukan pada masa mendatang. Berdasarkan Pasal 84 Perda No. 1 Tahun 2012 tentang pengembangan kawasan TOD dilakukan di terminal/stasiun antar moda di terminal angkutan umum massal, stasiun, dan pusat kegiatan yang saling menghubungkan dengan daerah di sekitarnya. Lokasi terminal/stasiun dengan konsep TOD ditetapkan di kawasan sebagai berikut:

1. Kawasan yang memiliki nilai ekonomi tinggi atau yang diprediksi bakal memiliki nilai ekonomi tinggi

2. Kawasan yang direncanakan atau dijadikan sebagai pusat kegiatan

Dengan kondisi tata ruang Jakarta yang memilik ketergantungan yang tinggi terhadap kendaraan pribadi, merupakan hal yang sulit untuk menerapkan rencana di atas tersebut. Sehingga, upaya untuk menerapkan konsep TOD ini berbagai langkah perlu dilaksanakan seperti antara lain menyiapkan konsep tentang investasi dan kebijakan, menetapkan rancangan yang berorientasi angkutan umum, mengatur ulang kebijakan penyediaan parkir, menyesuaikan regulasi tentang suatu pengembangan lahan, memperkuat moda transportasi yang mendukung angkutan umum (seperti pedestrian, jalur sepeda), memaksimalkan peluang koordinasi antar pemangku 
kepentingan dan menyesuaikan layanan angkutan umum terhadap keinginan/keperluan komunitas yang akan dilayani (CUTR, 2002).

\section{METODE PENELITIAN}

Metode pengumpulan data yang digunakan dalam penelitian ini adalah dengan melakukan penyebaran kuesioner Metodologi penelitian adalah ilmu yang mempelajari cara-cara melakukan pengamatan dengan pemikiran yang tepat dan melalui proses langkah-langkah yang disusun secara ilmiah untuk mencari, menyusun, menganalisis dan menyimpulkan data-data, sehingga dapat digunakan untuk mengembangkan dan menguji kebenaran sesuatu pernyataan. Metode yang akan digunakan dalam penelitian ini adalah dengan memberikan kuesioner secara online kepada narasumber.

\section{Metode pengumpulan data}

Untuk memperoleh data dalam penelitian ini, metode yang digunakan adalah kuesioner. Kuesioner adalah teknik pengumpulan data yang digunakan dalam metodologi penelitian kuantitatif). Dalam penelitian ini, peneliti menyebarkan kuesioner menggunakan google form.

\section{Kuisioner}

Pengukuran nilai kuesioner akan menggunakan teknik pengukuran dengan skala likert. Skala yang digunakan sebagai berikut: Keterangan untuk skala pengukuran tingkat frekuensi tentang pengembangan kawasan TOD di daerah Lebak Bulus adalah:

1. Tidak Baik

2. Kurang

3. Cukup

4. Baik

5. Sangat Baik

\section{HASIL DAN PEMBAHASAN}

Bab ini akan menyajikan hasil analisis dan pengolahan data yang dilakukan dengan menggunakan metode SPSS data survey dilakukan dengan metode penyebaran kuesioner. Survei tersebut memiliki syarat responden pernah menaiki MRT di dareah Lebak Bulus dan mengetahui are park and ride kemudian plaza transit yang berda disana. Pertanyaan yang diajukan pada survey terkait dengan kondsi lalu lintas di daerah Lebak Bulus, MRT, area park and ride, dan plaza transit. Kuesioner dibuat dengan menggunakan skala likert dengan nilai 1-5. Penelitian ini mempunyai responden sebanyak 100 orang. Responden ialah pihak adalah pihak yang terlibst secara langsung dengan keadaan lalu lintas di daerah Lebak Bulus, MRT, area park and ride, dan plaza transit.

\section{Karakterstik kuesioner}

Kuisioner dibagi menjadi 2 kriteria dimana X1 untuk MRT dan kendaran baik pribadi mupun kendaraan umum sedangkan X2 untuk area penunjang MRT. Penilaiannya dengan menggunakan skala likert dimana terdapat angka 1 sampai 5 . 1 berarti tidak baik, 2 berarti kurang baik, 3 berarti cukup, 4 berarti baik, dan yang terakhir adalah angka 5 yaitu sangat baik. Pertanyaan kuisioner dapat dilihat pada tabel 1.

Tabel 1. Daftar pertanyaan kuesioner

\begin{tabular}{cc}
\hline Variabel & Pertanyaan \\
\hline X1.1 & Kondisi stasiun MRT di daerah Lebak Bulus \\
X1.2 & Keinginan masyarakat untuk berjalan kaki menuju MRT Lebak Bulus \\
X1.3 & Penggunaan angkutan umum di daerah Lebak Bulus (teratur atau tidak teratur) \\
X1.4 & Penggunaan kendaraan pribadi di daerah Lebak Bulus (padat atau tidak padat) \\
\hline
\end{tabular}


Tabel 1. Daftar pertanyaan kuesioner (Lanjutan)

\begin{tabular}{lc}
\hline Variabel & Pertanyaan \\
\hline X1.5 & Jumlah penumpang di dalam MRT \\
X1.6 & Kapasitas penumpang dalam MRT \\
X1.7 & Ketepatan jadwal keberangkatan MRT \\
X1.8 & Keadaan di dalam MRT \\
X1.9 & Pelayanan di stasiun MRT \\
X1.10 & Ketepatan jadwal kedatangan MRT \\
X1.11 & Tarif biaya MRT \\
X1.12 & Keamanan di dalam MRT \\
X2.1 & Kondisi jalanan di area park and ride \\
X2.2 & Tarif biaya park and ride \\
X2.3 & Luas area park and ride \\
X2.4 & Keamanan di area Park And Ride \\
X2.5 & Jarak dari stasiun MRT menuju Plaza Transit \\
X2.6 & Luas area Plaza Transit \\
\hline
\end{tabular}

\section{Uji validitas}

Data yang telah didapatkan dari hasil survery kemudian dibuat dalam bentuk tabel pada Excel dan disimpan dengan format .CSV (Comma Delimited) agar file tersebut dapat diimport ke dalam program SPSS. Kemudian dilakukan uji validitas untuk stetiap karakteristik pertanyaan dimana dalam uji validitas ini jumlah $\mathrm{r}$ hitung yan didapat harus lebih besar ketimbang dengan $r$ tabel yang ada dimana jumlahnya adalah 0.1654 . Hasil uji vaaliditas dapat dilihat pada tabel 2 dan tabel 3.

Tabel 2. Uji validitas X1

\begin{tabular}{ccc}
\hline Pertanyaan & Rhitung & Rtabel \\
\hline X1.1 & 0,569 & 0,1654 \\
X1.2 & 0,521 & 0,1654 \\
X1.3 & 0,434 & 0,1654 \\
X1.4 & 0,422 & 0,1654 \\
X1.5 & 0,702 & 0,1654 \\
X1.6 & 0,605 & 0,1654 \\
X1.7 & 0,602 & 0,1654 \\
X1.8 & 0,678 & 0,1654 \\
X1.9 & 0,659 & 0,1654 \\
X1.10 & 0,614 & 0,1654 \\
X1.11 & 0,568 & 0,1654 \\
X1.12 & 0,620 & 0,1654 \\
\hline
\end{tabular}


Tabel 3. Uji validitas X2

\begin{tabular}{ccc}
\hline Pertanyaan & Rhitung & Rtabel \\
\hline X2.1 & 0,632 & 0,1654 \\
X2.2 & 0,755 & 0,1654 \\
X2.3 & 0,727 & 0,1654 \\
X2.4 & 0,746 & 0,1654 \\
X2.5 & 0,748 & 0,1654 \\
X2.6 & 0,731 & 0,1654 \\
\hline
\end{tabular}

Dari tabel diatas dapat disimpulkan bahwa pada karakteristik pertanyaan X1 dan X2 dapat dinyatakan valid karena semua $r$ hitung yang didapat lebih besar dibandingkan dengan $r$ tabel yang ada.

\section{Uji reabilitas}

Uji reabiltas pada penelitian ini menggunakan metode Cronbach's Alpha yang diuji dengan bantuan program statistik (SPSS). Berikut adalah hasil uji reabilitas X1 dapat dilihat dari tabel 4 dan tabel 5 di bawah ini:

Tabel 4.Uji Reabilitas X1

\begin{tabular}{ccc}
\hline Cronbach's Alpha & $\begin{array}{c}\text { Cronbach's Alpha Based on } \\
\text { Standardized Items }\end{array}$ & Nof Items \\
\hline 0,74 & 0,864 & 13 \\
\hline
\end{tabular}

Dari tabel datas diketahui bahwa nilai Cronbach's Alpha adalah sebesar 0,864 yang berarti memenuhi syarat dimana Cronbach's Alpha minimal adalah sebesar 0,6 agar dapat dilanjutkan.

Tabel 5.Uji Reabilitas X2

\begin{tabular}{ccc}
\hline Cronbach's Alpha & $\begin{array}{c}\text { Cronbach's Alpha Based on } \\
\text { Standardized Items }\end{array}$ & Nof Items \\
\hline 0,782 & 0,880 & 7
\end{tabular}

Dari tabel datas diketahui bahwa nilai Cronbach's Alpha adalah sebesar 0.880 yang berarti memenuhi syarat dimana Cronbach's Alpha minimal adalah sebesar 0.6 agar dapat dilanjutkan.

\section{Total jawaban terbanyak}

Total jawaban terbanyak X1dan X2 dapat dilihat pada tabel 6 dan tabel 7.

Tabel 6. Total jawaban terbanyak X1

\begin{tabular}{ccc}
\hline Pertanyaan & Skala Likert & Persentse \\
\hline X1.1 & Baik & $53 \%$ \\
X1.2 & Baik & $57 \%$ \\
X1.3 & Cukup & $48 \%$ \\
X1.4 & Cukup & $39 \%$ \\
X1.5 & Sangat Baik & $40 \%$ \\
X1.6 & Baik dan Sangat Baik & $43 \%$ \\
X1.7 & Sangat Baik & $49 \%$ \\
\hline
\end{tabular}


Tabel 6. Total jawaban terbanyak X1 (Lanjutan)

\begin{tabular}{ccc}
\hline Pertanyaan & Skala Likert & Persentse \\
\hline X1.8 & Sangat Baik & $49 \%$ \\
X1.9 & Sangat Baik & $48 \%$ \\
X1.10 & Sangat Baik & $50 \%$ \\
X1.11 & Cukup & $40 \%$ \\
X1.12 & Sangat Baik & $54 \%$ \\
\hline
\end{tabular}

Tabel 7. Total jawaban terbanyak X2

\begin{tabular}{ccc}
\hline Pertanyaan & Skala Likert & Persentse \\
\hline X2.1 & Baik & $48 \%$ \\
X2.2 & Baik & $52 \%$ \\
X2.3 & Baik & $57 \%$ \\
X2.4 & Baik & $39 \%$ \\
X2.5 & Baik & $49 \%$ \\
X2.6 & Baik & $48 \%$ \\
\hline
\end{tabular}

\section{Pendapat masyarakat atau responden tentang kawasan TOD di Lebak Bulus}

Di dalam kuisioner terdapat beberapa pendapat masyarakat tentang kawasan TOD di Lebak bulus yaitu:

1. Sangat baik untuk mempermudah perjalanan

2. Sangat membantu untuk majunya sistem transportasi di Lebk Bulus

3. Sangat baik untuk dikembangkan

4. Tujuan TOD Lebak Bulus cukup baik untuk transportasi di Jakarta

5. Dengan adanya konsep TOD dapat menyelesaikan berbagai permasalahan di jakarta khususnya daerah Lebak Bulus seperti kemacetan dan polusi udara yang tinggi

\section{Saran dari masyarakat atau responden}

Di dalam kusioner juga terdapat saran- saran dari masyarakat tentang kawasan TOD di Lebak Bulus:

1. Lebih ditingkatkan lagi kualitas fasilitas dan sistemnya agar masyarakat semakin nyaman dan yakin untuk menggunakan transportasi umum seperti MRT ini

2. Diperlukan penambahan pepohonan dan ruang terbuka agar pengunjung / pemakai MRT dpt merasakan kenyamanan dalam berpergian

3. Supaya ada akses dari rumah dengan kendaraan umum untuk menuju ke MRT, agar transportasinya bisa terintegrasi dengan lebih baik

4. Lebih ditingkatkan lagi pelayanannya

5. Agar tarif mrt dapat menyesuaikan kalangan pelajar/menengah ke bawah

6. Pertahankan kebersihan dan kenyamanannya

7. Menyediakan tempat duduk di area tidak berbayar 


\section{Rata- rata nilai berbobot untuk setiap pertanyaan}

Setiap masing- masing dari pertanyaan dicari nilai rata- ratanya. Berikut adalah nlai rata- rata yang dapat dilihat dari tabel 8.

Tabel 8. Rata- rata nilai setiap pertanyaan

\begin{tabular}{cc}
\hline Pertanyaan & Nilai rata- rata \\
\hline X1.1 & 4,2 \\
X1.2 & 3,85 \\
X1.3 & 3,46 \\
X1.4 & 3,58 \\
X1.5 & 4,13 \\
X1.6 & 4,27 \\
X1.7 & 4,42 \\
X1.8 & 4,42 \\
X1.9 & 4,37 \\
X1.10 & 4,43 \\
X1.11 & 3,76 \\
X1.12 & 4,44 \\
X2.1 & 4,11 \\
X2.2 & 3,96 \\
X2.3 & 3,88 \\
X2.4 & 3,94 \\
X2.5 & 3,94 \\
X2.6 & 4,08 \\
Rata- rata nilai penggunaan kendaraan pribadi dan & 4,14 \\
Rendaraan umum & 3,52 \\
\hline
\end{tabular}

\section{KESIMPULAN DAN SARAN}

\section{Kesimpulan}

Kesimpulan yang didapat adalah sebagai berikut:

1. Berdasarkan dari hasil penelitian diatas kebanyakan pengguna MRT adalah orang yang berusia sekitar 21-40 tahun yaitu sebanyak 56\% dan tidak responden yang berusia lebih dari 60 tahun. Hal ini menunjukkan bahwa MRT lebih banyak digunakan di kalangan pemuda.

2. Pada transportasi di daerah Lebak Bulus yaitu tentang keteraturan menggunakan angkutan umum dan kepadatan penggunaaan kendaran pribadi masing-masing mendapat nilai rata-rata dari responden yaitu, pada keteratuan angkutan umum mendapat nilai rata- rata sebesar 3,46 dan pada kepadatan penggunaan kendaraan pribadi mendapat nilai rata- rata sebesar 3,58. Hal ini menunjukkan bahwa keadaan transportasi Lebak Bulus baik dalam penggunaan kendaraan pribadi dan angkutan umum sudah cukup baik dan teratur.

3. Motivasi berjalan kaki menuju MRT Lebak Bulus nilai rata- rata dari responden yakni sebesar 3,85. Hal ini menunjukkan bahwa motivasi bejalan kaki masyarakat menuju stasiun MRT di daerah Lebak Bulus sudah cukup tinggi.

4. Kondisi di stasiun MRT mendapatkan nilai rata- rata dari responden yaitu sebesar 4,2, sedangkan kondisi didalam MRT mendapatkan nilai rata- rata dari responden sebesar 4,42. Hal ini menunjukkan 
daerah di sekitar MRT baik didalam maupun diluar MRT stasiun Lebak Bulus sudah baik.

5. Jumlah penumpang MRT dan kapasitas penumpang MRT mendapatkan nilai rata-rata dari responden dimana masing-masing 4,13 untuk pertanyaan pertama dan 4,27 untuk pertanyaan yang kedua. Hal ini menunjukkan bahwa cukup banyak penumpang yang ingin menggunakan MRT meskipun dalam keadaan pandemi seperti sekarang ditambah dengan kapasitas angkut dari MRT yang dapat mengangkut banyak penumpangdari satu tempat menuju tempat lain dengan cepat.

6. Pada ketepatan jadwal MRT yaitu pada ketepatan jadwal keberangkatan yaitu mendapat nilai rata- rata sebesar 4,42 dan pada ketepatan jadwal kedatangan mendapatkan nila 4,43. Hal ini menunjukkan bahwa jadwal MRT baik dalam keberangkatan maupun kedatangan sudah tepat waktu.

7. Tarif biaya MRT mendapatkan nilai rata- rata dari responden yaitu sebesar 3,76. Hal ini menunjukkan bahwa tarif MRT sebesar Rp. 15.000 sudah cukup baik,

8. Pada pelayanan dan keamanan di dalam stasiun MRT dan MRT masing- masing mendapat nilai ratarata yaitu 4,37 dan 4,44 untuk kedua pertanyaan tersebut. Hal ini menunjukkan bahwa pelayanan pegawai MRT sudah baik kepada pengguna MRT dan keamanan di dalam stasiun MRT pun dapat dikatakan sudah tinggi

9. Pada area park and ride terdapat 4 pertanyaan yaitu tentang kondisi jalanan, tarif biaya, luas area, dan keamanan di park and ride tersebut. Masing- masing mendapatkan jawaban rata- rata dari responden yakni dari pertanyaan 1 sampai 4 secara berurutan sebesar 4,11, 3,96, 3,88, 3,94. Hal ini menunjukkan bahwa park and ride sebagai salah satu sarana penunjang MRT di daerah Lebak Bulus dapat disimpulkan sudah baik.

10. Salah satu penunjang MRT selain park and ride yaitu plaza transit juga mendapatkan respon positif dari responden, yakni mendapat nilai rata-rata sebesar 3,94 untuk jarak dari stasiun MRT menuju plaza transit dan 4,08 luas area plaza transit tersebut. Hal ini menunjukkan bahwa jarak dari plaza transit menuju stasiun MRT sudah cukup terjangkau dan luas area plaza transit dapat dikatakan sudah luas dan mendapat nilai positif dari responden.

Dari hasil kuisioner diatas dapat disimpulkan bahwa MRT, park and ride, dan plaza transit yang berada di daerah Lebak Bulus dapat dikatakan mendapatkan nlai yang baik atau positif dari responden dengan nlai rata- rata sebesar 4,14. Hal ini juga meningkatkan tingkat kelancaran lalu lintas di daerah Lebak Bulus dimana nilai rata- rata dari penggunaan kendaraan pribadi dan kendaraan umum yakni sebesar 3,52 dan berdasarkan rata- rata tersebut dapat disimpulkan bahwa lalu lintas di daerah lebak bulus sudah cukup baik atau cukup lancar.

\section{Saran}

Saran yang dapat diberikan adalah sebagai berikut:

1. Diperlukan penambahan pepohonan agar udara menjadi lebih segar lagi dan semakin banyak lagi masyarakat yang berjalan kaki menuju MRT Lebak Bulus.

2. MRT semakin lama semakin berkembang sebagai sistem transportasi di daerah Lebak Bulus, masyarakat sekarang memang sudah puas dengan luas area park and ride, tetapi ketika nanti semakin berkembang dan pengguna MRT semakin banyak akan lebih baik jika luas area park and ride ditambah menjadi lebih besar agar memudahkan masyrakat yang membawa kendaraan seperti untuk menuju kesana.

3. Ditambah lagi area jangkauan MRT agar bisa memudahkan masyarakat pergi ke berbagai tempat.

Bedasarkan hasil kuisioner diatas tentang MRT, park and ride, dan plaza transit mayoritas responden menjawab baik dan sangat baik, tetapi pada bagian tarif biaya MRT mayoritas responden menjawab cukup, hal itu menunjukkan bahwa tarif MRT masih bisa dilakukan evaluasi seperti penurunan tarif pada hari libur atau tanggal merah atau bisa juga dengan menggratiskan pengguna MRT usia 60 tahun ke atas dengan cara menunjukkan KTP kepada petugas disana.

\section{DAFTAR PUSTAKA}

Griffin, Kenneth W. "Building Type Basic for Transit Facilities.” Victoria Transport Policy Institute.2014 Porter, D.’Transit-Focused Development: A Progress Report." Autumn. 1998

CUTR."Building Transit Oriented Development in Established Communities."Center For Urban Transportation Research University of South Florida.2002

“TOD Standard. Despachio.” New York: Institute for Transportation Development Policy. 2015

"Transit-Oriented Development and Joint Development in the United States: A Literature Review." Washington DC: Transit Cooperative Research Program. 2002 
